\title{
Influences of nutritional state and temperature on suspension-feeding rates and mechanics in the spionid polychaete Polydora cornuta
}

\author{
Jeff Shimeta*, Peter F. Witucki, Karen R. Hippe \\ Biology Department, Franklin \& Marshall College, PO Box 3003, Lancaster, Pennsylvania 17604-3003, USA
}

\begin{abstract}
Benthic suspension feeders can respond to variations in food resources by behavioral and physiological means, but little is known about their ability to adjust the mechanics of particle capture. We examined influences of nutritional state (i.e. growth rate as influenced by food level) and temperature on suspension-feeding mechanics of the spionid polychaete Polydora cornuta (previously P. ligni). Worms were conditioned for 5 to $10 \mathrm{~d}$ in 4 treatments including 2 levels of suspended

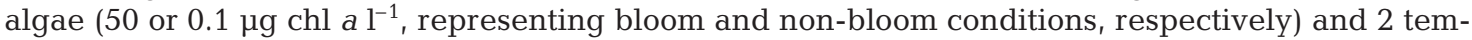
peratures $\left(15\right.$ or $5^{\circ} \mathrm{C}$, representing temperate spring/summer and winter, respectively). Both of these factors had significant, direct influences on growth rate. Worms of equal body size were then video taped while suspension feeding in a flume at their respective temperatures but with identical concentrations of food, including polystyrene beads for observing feeding mechanics. Worms with the lower growth rate captured beads at a rate $2.1 \times$ that of worms with the higher growth rate, and worms at $15^{\circ} \mathrm{C}$ captured beads at a rate $1.9 \times$ that of worms at $5^{\circ} \mathrm{C}$, with no interactions between these factors. Particle contact rates did not differ among treatments; rather, the results were due solely to altered retention efficiencies (the proportion of contacted particles that were captured). Further experiments indicated that worms with the lower growth rate had enhanced adhesive strength of the mucous coating that retains particles on the palps and that low temperature inhibited the effectiveness of cilia in aiding retention. This is the first evidence that a benthic suspension feeder modifies the retention efficiency on its appendages, which it does in response to changes in its nutritional state. The enhancement of retention by mucus when under nutritional stress should act as a compensatory response at times or places of sparse food.
\end{abstract}

KEY WORDS: Suspension feeding $\cdot$ Retention efficiency $\cdot$ Spionid $\cdot$ Polychaete $\cdot$ Nutritional state $\cdot$ Temperature

Resale or republication not permitted without written consent of the publisher

\section{INTRODUCTION}

Benthic suspension feeders experience highly variable food resources in time and space (Berg \& Newell 1986, Fegley et al. 1992, Navarro \& Thompson 1995). Because growth and reproduction are often food limited (Wilson 1985, Riisgard et al. 1996, Rossi \& Lardicci 2002), animals' responses to variations in food supply may be important determinants of fitness. Suspension feeders and interface feeders (which switch between suspension feeding and deposit feeding at the sediment-water interface) are known to respond to fluctuations or patchiness of food in a variety of ways, including behavioral (Taghon et al. 1980, Dauer et al. 1981, Jordana et al. 2000, Kihslinger \& Woodin 2000) and physiological adjustments (Bayne 1993, Riisgard \& Larsen 2000, Velasco \& Navarro 2002, Ward et al. 2003).

Another possible response to varying food resources which has received little attention is adjustment of suspension-feeding mechanics. Food-particle capture by suspension feeders is a 2-step mechanical process: initial contact followed by retention. Studies of suspen- 
sion-feeding mechanics at the level of contact and retention can help to predict the types and amounts of food particles captured (Loudon 1990, Shimeta \& Koehl 1997, Allen 1998), and might reveal ways that animals can adjust to variable food conditions (Ward \& Shumway 2004).

Many studies have examined the dependence of capture rates on variables such as flow, appendage morphology and particle characteristics without examining contact or retention directly (reviewed by Shimeta \& Jumars 1991). Often in this approach, the underlying mechanisms explaining the results remain unknown. Mechanical and behavioral aspects of particle contact (or 'encounter') have been modeled, measured and reviewed extensively (Rubenstein \& Koehl 1977, LaBarbera 1984, Shimeta \& Jumars 1991, Shimeta 1993, Loo et al. 1996, Shimeta \& Koehl 1997, Wildish \& Kristmanson 1997, Palmer et al. 2004), but less is known about particle retention after contact.

Benthic suspension feeders retain contacted particles by the use of mucus, cilia, nematocysts or sievelike structures on which particles are trapped. The retention efficiency (i.e. the proportion of contacted particles that are captured) depends on flow speed, particle size, particle hydrophobicity and electrostatic charge, appendage size, or mesh size of a sieve (LaBarbera 1978, 1984, Loudon 1990, Shimeta \& Jumars 1991, Shimeta \& Koehl 1997, Allen 1998, Conova 1999). An important unresolved question is whether animals can adjust their retention efficiency in response to changes in food resources. Particularly when contact rate is low, an ability to adjust retention efficiency would be advantageous. Shimeta \& Jumars (1991) speculated that suspension feeders might enhance the adhesive strength of a mucus-coated feeding appendage when food concentrations are low or when drag forces on contacted particles are high.

We examined the effects of nutritional state (i.e. growth rate as influenced by food level) on feeding mechanics of the spionid polychaete worm Polydora cornuta (previously P. ligni, Blake \& Maciolek 1987). P. cornuta, like many spionids, is common in intertidal and shallow subtidal communities (Dauer et al. 1981, Zajac \& Whitlatch 1982). They are interface feeders, switching between suspension feeding and deposit feeding in response to flow speed and food resources (Taghon et al. 1980, Dauer et al. 1981, Bock \& Miller 1996). Suspension feeding is an important feeding mode in that it can enhance growth rates dramatically (Taghon \& Greene 1992, Hentschel 2004). The worms collect particles on 2 ciliated palps, using mucus to retain and transport captured particles to the mouth along a median ciliated groove on the palp (Dauer 1987, 1994).

We manipulated nutritional state by maintaining worms in suspended-food concentrations representing phytoplankton bloom or non-bloom conditions. Because food level in the field covaries with temperature, and temperature might confound any physiological response to food conditions, we also manipulated temperature independently of food level. We found that nutritional state and temperature have different independent effects on feeding mechanics, both operating at the step of particle retention.

\section{MATERIALS AND METHODS}

Worm collection and conditioning. Polydora cornuta were collected at low tide from an intertidal sand flat at Shark River Island (New Jersey, USA) during June-August. Worm tubes were collected on finemesh sieves from sediment located ca. $0.1 \mathrm{~m}$ above mean low water and ca. $25 \mathrm{~m}$ seaward of a Spartina salt marsh. They were transported to Franklin \& Marshall College (Pennsylvania, USA) and placed in artificial seawater $(30 \%)$ at $15^{\circ} \mathrm{C}$. The day after collection, worms were teased from their tubes and anesthetized briefly in $4 \% \mathrm{MgCl}_{2}$ in seawater while body volumes were measured. An image of each worm laying on its side under a dissecting microscope was captured and body width was measured at 5 positions (first segment, last segment and at 3 equidistant points between), thus defining 4 body regions. The volume of each region was calculated as a conical frustum (volume $=[\pi L / 3]\left[r^{2}\right.$ $\left.+r q+q^{2}\right]$, where $L=$ length of region, $r=$ anterior radius and $q=$ posterior radius) and these volumes were summed to yield total body volume. After recovering from the anesthetic, each worm was allowed to burrow into the large end of a vertically held plastic pipettor tip $(0.75 \mathrm{~cm}$ inner diameter) that was sealed at the narrow bottom end and filled with defaunated sediment from the field site (sieved through a $250 \mu \mathrm{m}$ mesh and dried). Only worms that burrowed immediately and constructed tubes shortly thereafter were used for experiments, which began the same day.

To manipulate nutritional state, each worm was conditioned for 5 to $10 \mathrm{~d}$, depending on the experiment, in 1 of 4 treatments that included 2 levels of suspended

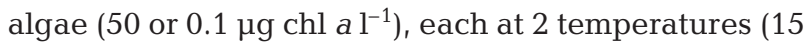
or $5^{\circ} \mathrm{C}$ ). These algal concentrations occur naturally in coastal waters during bloom and non-bloom conditions, respectively (Lin \& Hines 1994, Navarro \& Thompson 1995, Hughes et al. 2000, Lucas et al. 2000) and these temperatures correspond to temperate-zone spring/summer and winter conditions, respectively (Vedel 1998, Hughes et al. 2000, Jordana et al. 2000). Each worm was conditioned separately, with its pipettor tip held upright, in a plastic container holding $4.5 \mathrm{l}$ of artificial seawater and with vigorous aeration to maintain algae in suspension. The algae were a mix- 
ture of Thalassiosira, Isochrysis, Pavlova and Chaetoceros (cell sizes 5 to $16 \mu \mathrm{m}$ ) purchased in concentrate from Reed Mariculture. Concentrations of suspended chl $a$ were measured daily in each worm's container using a Turner TD-700 fluorometer (in vivo mode) and additional algae were added as needed to maintain constancy.

Preliminary growth rate experiment. Influences of the conditioning treatments on nutritional states were determined by measuring growth rates. For this experiment, worms in all treatments had equal average body volume at the beginning of the conditioning period. Worms in the range of 0.17 to $0.48 \mathrm{~mm}^{3}$ body volume (4.3 to $5.9 \mathrm{~mm}$ body length) were assigned randomly to the 4 treatments. After $7 \mathrm{~d}$ of conditioning, worms were recovered from the pipettor tips, anesthetized and their body volumes were measured again as described above. Volume-specific growth rate was calculated as $\ln \left(V_{\mathrm{f}} / V_{\mathrm{i}}\right) / d$, where $V_{\mathrm{f}}=$ final volume, $V_{\mathrm{i}}=$ initial volume and $d=$ number of days conditioned. Growth rate and final body volume were each tested by 2 -factor ANOVA for significant effects of food level and temperature.

Feeding experiment. Influences of the conditioning treatments on suspension-feeding mechanics were measured on worms conditioned in the same manner as above except that the body volumes at the beginning of the conditioning period differed systematically among the treatments. Using the results from the preliminary growth rate experiment, we set the initial body volumes such that the final body volumes would be equal when we observed feeding at the end of the conditioning period. This manipulation allowed worms in the various treatments to have different growth rates but equal body sizes at the time of observation, thus preventing confounding effects of body size on feeding mechanics (Shimeta \& Koehl 1997). The worms were conditioned for 5 to $10 \mathrm{~d}$ because feeding observations could not be completed in a single day.

Feeding observations were made in a recirculating flume with a $1.75 \mathrm{~m}$ straight channel of $25 \mathrm{~cm}$ width, operated with a $5 \mathrm{~cm}$ water depth. Turbulence is dampened at the entrance by a flow straightener of packed straws $10 \mathrm{~cm}$ long and $0.5 \mathrm{~cm}$ in diameter. Worms were positioned $95 \mathrm{~cm}$ downstream of the flow straightener and $8.5 \mathrm{~cm}$ from the side wall of the channel. At the exit of the flume, water spills over a weir into a separated reservoir from which it is pumped back to the entrance. The total water volume in the channel and reservoir was $45.4 \mathrm{l}$. For all observations, flow speed was $6.0 \mathrm{~cm} \mathrm{~s}^{-1}$ measured at $0.5 \mathrm{~cm}$ above the bottom with a TSI Flowpoint hot-film anemometer.

For each worm observed, the flume was filled with artificial seawater of the appropriate temperature (5 or $15^{\circ} \mathrm{C}$, matching that worm's conditioning tempera- ture), passed through a $5 \mu \mathrm{m}$ filter bag and supplemented with 1000 polystyrene beads $\mathrm{ml}^{-1}$ as well as a chemical feeding stimulant. Beads were used rather than natural particles because beads are round, smooth and uniform, thereby avoiding variation in capture mechanics due to variable geometries, surface features and orientations of natural particles. The beads were spherical with specific gravity 1.02 and size range 75 to $90 \mu \mathrm{m}$ (SoloHill Engineering). This size range is appropriate for spionids suspension feeding at the sediment-water interface, where their diet includes large organic-mineral aggregates, pennate diatoms, detritus and mineral grains up to or exceeding $100 \mu \mathrm{m}$ (Muschenheim 1987). The feeding stimulant was prepared by grinding $4.5 \mathrm{~g}$ of dry Gerber ${ }^{\circledR}$ mixed baby cereal, suspending it in artificial seawater and passing it through a $15 \mu \mathrm{m}$ mesh. Thus, at the time of observation, each worm was maintained at its conditioned temperature, but all worms were given identical feeding resources: plastic beads (which we observed being captured), dissolved and particulate organic matter $\leq 15 \mu \mathrm{m}$ (generally too small to be seen), and no algae. The pipettor tip with the worm was placed in a hole in the flume bed such that the sediment surface was flush with the bottom. After a single worm was video taped in side view for $30 \mathrm{~min}$, it was removed and the flume was drained and refilled with new water, beads and feeding stimulant for the next worm. Worms were observed in randomized order.

Feeding was recorded through the side wall of the flume on SVHS video tapes using a Panasonic AG7350 video cassette recorder and a Watec WAT-502A CCD camera equipped with a Nikon Micro-Nikkor $105 \mathrm{~mm}$ macro lens and Nikon PB-6 extension bellows. Worms were illuminated from above with a fiber-optic lamp covered with red acetate to avoid disturbance.

Immediately after video taping each worm, it was recovered from the pipettor tip, anesthetized and its final body volume was measured as described above. Final body volume and volume-specific growth rate were each tested by 2 -factor ANOVA for significant effects of conditioned food level and temperature.

Anesthetic experiment. To exclude the roles of ciliary and muscular activity on feeding performance, a feeding experiment was run as described above except that worms were anesthetized while in the flume. The flume contained $4 \% \mathrm{MgCl}_{2}$ (to stop muscular activity) and $2 \% \mathrm{LiCl}_{2}$ (to stop ciliary activity) in artificial seawater, in addition to the beads and feeding stimulant. These were the minimal chemical concentrations required to produce the desired effects while still allowing quick recovery after worms were returned to pure seawater, as determined in preliminary tests with a range of concentrations applied to worms in petri dishes. Prior to placing a worm in the flume, it was 
removed from its tube and anesthetized in these chemicals. The worm was held in the flume using 2 atraumatic surgical vessel clamps (Moria), one holding the anterior end of the body on the flume bed and the other holding the 2 palps straight upward with the frontal grooves facing upstream. Both clamps were held from positions downstream of the worm in order to avoid creating flow artifacts. After video taping, the worm was removed and the flume was refilled with new water and constituents. Worms were run in randomized order. Final body volumes were measured; these and volume-specific growth rates were each tested statistically as above.

Analyses of video tapes. Video tapes were observed frame-by-frame on a monitor. A particle contact was defined as occurring when a bead stopped on a palp for at least 1 frame or bounced off a palp, regardless of whether it was successfully captured. A particle capture was defined in the feeding experiment as occurring when a bead stopped and was then transported along a palp by cilia, regardless of whether it eventually entered the tube (i.e. some beads were subsequently lost or released but were still considered to have been captured). In the anesthetic experiment, captured beads could not be transported along the palp; however, beads that stopped on a palp for more than 2 frames were rarely lost, except when dislodged by another approaching bead. Thus, a particle capture was defined easily as occurring when a bead remained stopped on a palp.
Contact rate was calculated over the time it took a worm to contact 50 beads. Retention efficiency was calculated as the number of captures during this time divided by 50 contacts. Capture rate was calculated over the time it took a worm to capture 50 beads. Periods during which the worm was not suspension feeding were excluded from the analysis. Contact rate, arcsine-transformed retention efficiency and capture rate in the feeding experiment were each tested by 2-factor ANOVA for significant effects of conditioned food level and temperature. In the anesthetic experiment, only arcsine-transformed retention efficiency was tested.

\section{RESULTS}

\section{Growth rates}

In all experiments, growth rates during the conditioning period were directly related to food level and to temperature (Table 1). Thus, the differences in food level among treatments were sufficient to influence nutritional state as defined in the 'Introduction'. This result was consistent whether worms began the conditioning period at equal body volumes (Preliminary Growth Experiment) or ended the conditioning period at equal body volumes (Feeding and Anesthetic Experiments; Table 2). The interaction between food level and temperature was significant only in the latter 2 experiments (Table 1), wherein food level had its

Table 1. Polydora cornuta. Mean volumetric specific growth rate $\left(\mathrm{d}^{-1} ;\right.$ mean $\left.\pm \mathrm{SE}, \mathrm{n}\right)$ of worms during the conditioning period at 2 concentrations of algae and 2 temperatures. Low food level $=0.1 \mu \mathrm{g} \mathrm{chl} \mathrm{a} \mathrm{l^{-1 }}$; High food level $=50 \mu \mathrm{g} \mathrm{chl} \mathrm{al}^{-1}$. Results from 2 -factor ANOVA: Preliminary Growth Rate Experiment (Food $p<0.001$, Temperature $p=0.002$, Food $\times$ Temperature $p=0.11$ ), Feeding Experiment (Food $p<0.001$, Temperature $p<0.001$, Food $\times$ Temperature $p=0.002$ ), Anesthetic Experiment $($ Food $p<$ 0.001 , Temperature $\mathrm{p}<0.001$, Food $\times$ Temperature $\mathrm{p}<0.001$ )

\begin{tabular}{llcll}
\hline Experiment & \multicolumn{2}{c}{ Low food level } & \multicolumn{2}{c}{ High food level } \\
& \multicolumn{1}{c}{$5^{\circ} \mathrm{C}$} & $15^{\circ} \mathrm{C}$ & $5^{\circ} \mathrm{C}$ & \\
\hline Preliminary Growth Rate & $0.039( \pm 0.019,6)$ & $0.063( \pm 0.017,6)$ & $0.078( \pm 0.006,7)$ & $0.15( \pm 0.010,9)$ \\
Feeding & $0.034( \pm 0.010,16)$ & $0.053( \pm 0.013,18)$ & $0.062( \pm 0.009,16)$ & $0.15( \pm 0.010,18)$ \\
Anesthetic & $0.048( \pm 0.014,8)$ & $0.058( \pm 0.009,10)$ & $0.067( \pm 0.012,9)$ & $0.18( \pm 0.014,10)$
\end{tabular}

Table 2 . Mean body volume $\left(\mathrm{mm}^{3} \pm \mathrm{SE}, \mathrm{n}\right)$ of worms conditioned at 2 concentrations of algae and 2 temperatures. Low food level $=$

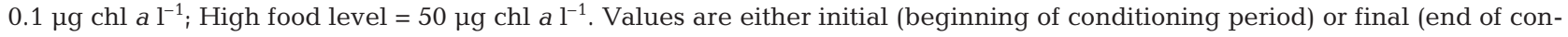
ditioning period), as indicated. Results from 2-factor ANOVA: Preliminary Growth Rate Experiment (Food $p=0.26$, Temperature $p=0.68$, Food $\times$ Temperature $p=0.73$ ), Feeding Experiment (Food $p=0.62$, Temperature $p=0.42$, Food $\times$ Temperature $p=0.65)$, Anesthetic Experiment (Food $p=0.71$, Temperature $p=0.16$, Food $\times$ Temperature $p=0.060$ )

\begin{tabular}{|llccc|}
\hline Experiment & \multicolumn{2}{c}{ Low food level } & \multicolumn{2}{c|}{ High food level } \\
& \multicolumn{1}{c}{$5^{\circ} \mathrm{C}$} & \multicolumn{1}{c}{$15^{\circ} \mathrm{C}$} & $5^{\circ} \mathrm{C}$ & \\
\hline Preliminary Growth Rate (initial) & $0.34( \pm 0.04,6)$ & $0.31( \pm 0.05,6)$ & $0.28( \pm 0.04,7)$ & $0.28( \pm 0.02,9)$ \\
Feeding (final) & $0.48( \pm 0.05,16)$ & $0.42( \pm 0.03,18)$ & $0.48( \pm 0.04,16)$ & $0.46( \pm 0.06,18)$ \\
Anesthetic (final) & $0.50( \pm 0.06,8)$ & $0.48( \pm 0.05,10)$ & $0.42( \pm 0.04,9)$ & $0.60( \pm 0.06,10)$ \\
& & & & \\
\hline
\end{tabular}




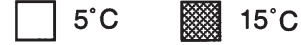

\section{A. Particle contact rate}

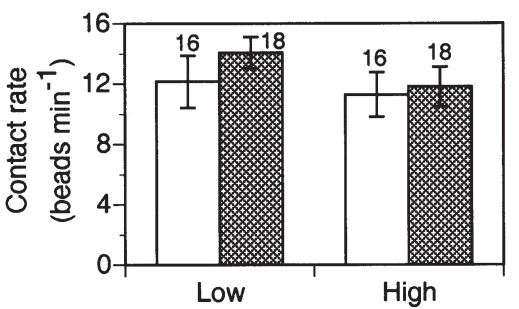

B. Particle retention efficiency

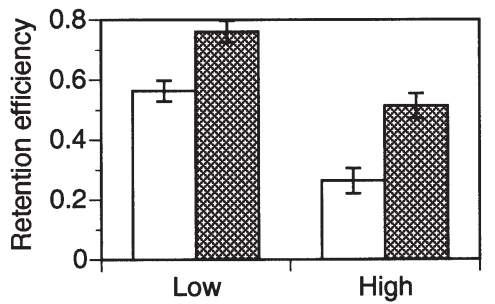

C. Particle capture rate

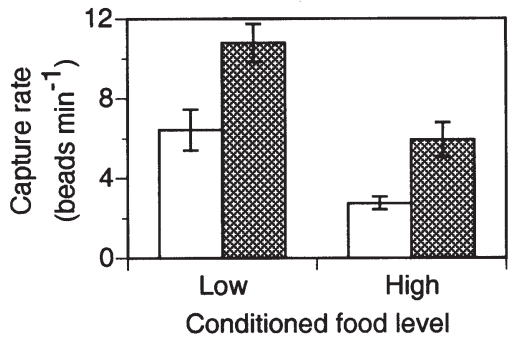

Fig. 1. Polydora cornuta. (A) Particle contact rate, (B) retention efficiency (proportion of contacted particles that were captured) and $(C)$ capture rate (mean $\pm \mathrm{SE}$ ) for worms conditioned at 2 concentrations of algae and 2 temperatures. Low

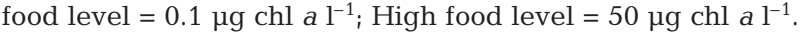
Sample sizes are shown above bars in (A). Results from 2factor ANOVA: (A) Food $p=0.27$, Temperature $p=0.39$, Food $\times$ Temperature $p=0.62$; (B) Food $p<0.001$, Temperature $\mathrm{p}<0.001$, Food $\times$ Temperature $\mathrm{p}=0.50$ (all from arcsinetransformed data); (C) Food $\mathrm{p}<0.001$, Temperature $\mathrm{p}<0.001$, Food $\times$ Temperature $\mathrm{p}=0.49$

greatest influence on growth rate in the high-temperature treatments and temperature had its greatest influence in the high food level treatments. This interaction was likely due to the differing initial body sizes, which were smaller in the high-temperature and the high food level treatments.

\section{Feeding experiment}

Contact rates were not significantly different among treatments (Fig. 1A). However, despite equal bead concentrations and the equal contact rates, worms conditioned at the low food level captured beads at significantly higher rates than worms conditioned at the high food level by an average factor of 2.1 (Fig. 1C). Also, worms that were conditioned and video taped at $15^{\circ} \mathrm{C}$ had significantly higher capture rates than worms at $5^{\circ} \mathrm{C}$ by an average factor of 1.9 (Fig. 1C). There were no significant interactions between conditioned food level and temperature.

The differences in capture rates corresponded to differences in retention efficiencies (Fig. 1B). The retention efficiency of low food level worms was on average $1.8 \times$ greater than that of high food level worms and that of worms at $15^{\circ} \mathrm{C}$ was on average $1.7 \times$ greater than that of worms at $5^{\circ} \mathrm{C}$. Again, there were no significant interactions.

To assess influences of the conditioned food level and temperature on ciliary activity, the velocity at which captured beads were transported toward the mouth in the frontal ciliated groove at the proximal end of the palps was measured from the video tapes of this experiment. Only temperature had a significant effect, with worms at $15^{\circ} \mathrm{C}$ transporting beads on average $2.0 \times$ faster than worms at $5^{\circ} \mathrm{C}$ (Fig. 2).

\section{Anesthetic experiment}

When worms were anesthetized with $\mathrm{MgCl}_{2}$ and $\mathrm{LiCl}_{2}$ to inhibit muscular and ciliary activity, retention efficiency was influenced only by the conditioned food level, not by temperature (Fig. 3). The retention efficiency of low food level worms was on average $2.6 \times$ greater than that of high food level worms. Retention efficiencies of all anesthetized worms were on average only $0.2 \times$ those of the conscious worms in the feeding experiment (compare Figs. 1B \& 3), probably because

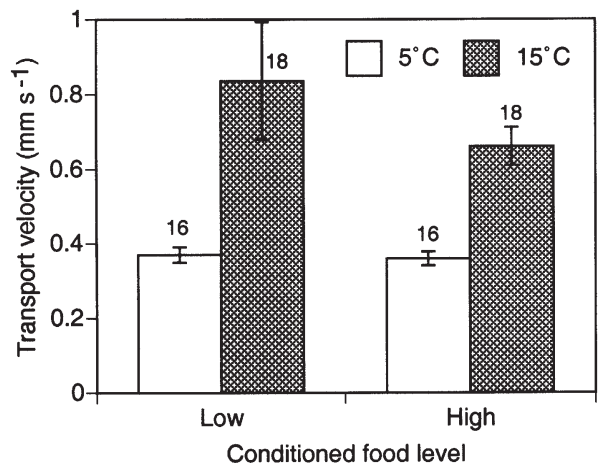

Fig. 2. Polydora cornuta. Transport velocity (mean \pm SE) of captured particles on the palps of worms in the experiment shown in Fig. 1. Sample sizes are shown above bars. Results from 2-factor ANOVA: Food $p=0.30$, Temperature $p<0.001$, Food $\times$ Temperature $\mathrm{p}=0.36$ 


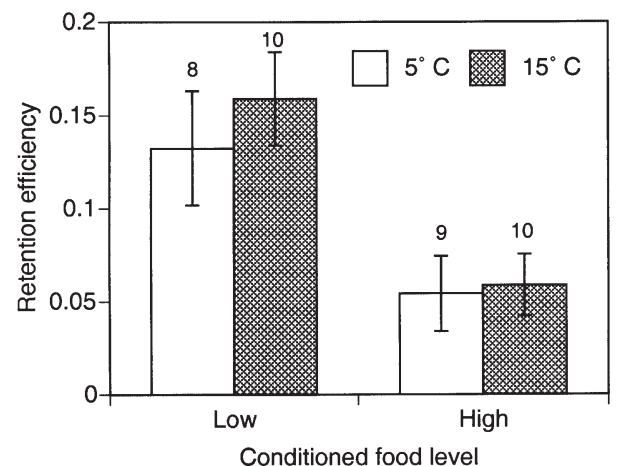

Fig. 3. Polydora cornuta. Particle retention efficiency (proportion of contacted particles that were captured, mean \pm SE) for worms conditioned at 2 concentrations of algae and 2 temperatures, and anesthetized with $\mathrm{MgCl}_{2}$ and $\mathrm{LiCl}_{2}$. Low food

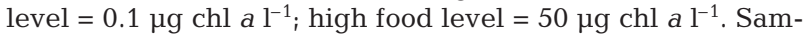
ple sizes are shown above bars. Results from 2-factor ANOVA: Food $\mathrm{p}<0.001$, Temperature $\mathrm{p}=0.36$, Food $\times$ Temperature $\mathrm{p}=0.92$ (all from arcsine-transformed data)

of the lack of muscular and ciliary action in the anesthetized worms. Contact and capture rates in the anesthetic experiment could not be compared meaningfully with those in the feeding experiment because the clamp holding the relaxed palps left considerably less palp length exposed to the flow.

After use in this experiment, some worms were immediately stained with Alcian blue, which revealed mucus on their palps and body in amounts similar to those of other worms that were never anesthetized or used in any experiments. After returning to pure artificial seawater, worms used in this experiment rapidly recovered and burrowed into sediment.

\section{DISCUSSION}

\section{Influences of nutritional state and temperature}

Under identical feeding conditions, worms in a relatively poor nutritional state, i.e. fed sparsely and having a low growth rate, captured particles at twice the rate of worms that had been fed abundantly and were in a state of faster growth. Capture rates were also directly related to temperature. Differences in capture rates must be due to differences in contact rates, retention efficiencies or both. These results were due exclusively to differences in retention efficiencies.

It was conceivable that contact rates could vary with temperature or nutrional state, e.g. if the morphology, orientation or behavior of the palps were altered. We observed no such effects, however, and their absence leaves retention efficiency as the sole explanation for the changes in capture rates.
Three mechanisms contribute to particle retention after contact on the palps of Polydora cornuta and many similar spionids, and we can infer which of these mechanisms are influenced by nutritional state and which by temperature. First, mucus is secreted on the frontal groove of the palps, along which particles are transported to the mouth (Dauer 1994, Qian \& Chia 1997). This mucus may be particularly important for retention of particles that strike the frontal groove. Second, cilia may aid retention, especially the laterofrontal cirri which are present on either side of the frontal groove and deflect contacted particles into the groove (Dauer 1987, Dauer et al. 2003). Finally, muscular action of the palp might be important in 2 ways. Orientation of the palps with respect to the flow might optimize contact geometry to facilitate retention, e.g. ensuring that particles strike squarely on the frontal groove or at the proper angle so that latero-frontal cirri can deflect them effectively. Also, the edges of the frontal groove can wrap around particles (Dauer 1985), which is important for post-capture transport but might also play some role in initial retention.

We conclude that the observed influence of nutritional state on particle retention was caused by a modification of mucous adhesion. When ciliary and muscular action were disabled in the anesthetic experiment, sparsely fed worms still had higher retention efficiencies than abundantly fed worms, as in the experiment with conscious worms. Therefore, mucus remains the only explanation for this result. Enhanced mucous adhesion of particles could have been caused by increased mucous production or by a change in mucous properties that increased its stickiness. Dauer (1983) suggested that the adhesive strength of mucus differs between species of spionids that face different strengths of flow forces in the field, but ours is the first known instance of a single species modifying its adhesive strength in response to environmental or physiological conditions.

Ciliary and muscular action nonetheless appear to play important roles in particle retention, because retention efficiencies declined dramatically when worms were anesthetized. Some of this decline could also have resulted because the frontal grooves of the palps may not have faced upstream as well as they do in conscious animals.

We infer that the influence of temperature on particle retention was caused by temperature-dependent ciliary action. Temperature influenced retention only when cilia were active in the conscious worms, not when cilia were inactivated in the anesthetized worms. Corroborating evidence is that the velocity of particle transport along the palps, which is a ciliary process, was also temperature dependent with a $Q_{10}$ effect of 2.0. Transport velocity should depend on ciliary beat 
frequency, which has a similar $Q_{10}$ effect (measured on bivalve gills, Jorgensen 1990). The success of laterofrontal cirri in deflecting contacted particles into the frontal groove could likewise be temperature dependent, thus explaining the observed influence of temperature on retention efficiency. Direct relationships between temperature and feeding rate have been reported for other suspension feeders such as bivalves, bryozoans and other polychaetes (Jorgensen 1990, Vedel 1998, Lisbjerg \& Petersen 2001).

\section{Ecological implications}

The adjustment of retention efficiency when under nutritional stress is a physiological response that acts to compensate for sparse food resources, e.g. the enhanced mucous adhesion on worms in the poor nutritional state here caused a doubling of particlecapture rate. This adjustment could be important to maintain sufficient energy uptake in low-food situations, where growth and reproduction can be food limited (Wilson 1985, Riisgard et al. 1996, Rossi \& Lardicci 2002). Adjustment of mucous adhesion might act in response to temporal or spatial variations in food levels. For example, when a phytoplankton population declines after a spring bloom, the worms' retention efficiency and capture rate could compensate at least partially, as seen in our data comparing the $15^{\circ} \mathrm{C}$ high food level treatment to the $15^{\circ} \mathrm{C}$ low food level treatment (Fig. 1). Likewise, retention and capture could compensate at a site with low food concentration compared to one with high food concentration. An important finding is that there were no interactions between nutritional state and temperature in any of the measures of feeding mechanics. Therefore, compensation for nutritional stress should occur regardless of season. It is also of interest to compare across both temperature and nutritional state, e.g. the spring-bloom condition (our $15^{\circ} \mathrm{C}$ high food level treatment) versus the winter condition (our $5^{\circ} \mathrm{C}$ low food level treatment). Under the winter conditions, the enhanced mucous adhesion compensated completely for the reduced ciliary effectiveness caused by the low temperature, and thus the retention efficiency was the same as in the springbloom condition (Fig. 1). We did not, however, determine limits on the time scale for mucous compensation, e.g. whether it can occur over a period much shorter than a week, or whether it continues during long-term (seasonal) acclimation to low food levels.

The fact that enhanced retention efficiency occurred only in the poor nutritional state suggests that it may not be energetically profitable in the well-fed state. When food is abundant, i.e. not limiting to growth or reproduction, the benefit of enhanced retention may be smaller than the cost. In contrast, when food is sparse, the benefit presumably exceeds the cost.

Like many spionids, Polydora cornuta is an interface feeder, switching between suspension and deposit feeding (Dauer et al. 1981). The mechanics of these feeding modes are similar in that particles are first contacted and then retained by adhesive mucus (Jumars et al. 1982, Hentschel 1996). The enhanced mucous adhesion seen here in nutritionally stressed worms that were suspension feeding would presumably also increase their retention efficiency and capture rate while deposit feeding.

Models and measurements of particle capture by suspension feeders often assume that retention efficiency is a constant equal to 1.0 (Shimeta \& Jumars 1991, Loo et al. 1996). Here, we observed retention efficiency to be neither large nor constant, but varying in response to temperature and nutritional state by different, independent mechanisms. Variable retention efficiency among food particles based on particle characteristics, flow speed and appendage size has previously been shown to be an important mechanical determinant of selective feeding (Loudon 1990, Shimeta \& Koehl 1997, Allen 1998, Conova 1999). Here, we found the first evidence that a benthic suspension feeder can modify the retention efficiency on its appendages, which it does in a manner that compensates for low food availability by enhancing its capture rate.

Acknowledgements. We thank B. Hentschel for assistance, advice and comments on the manuscript, and 3 anonymous reviewers for their comments. This work was supported by NSF grant OCE-9909241 and Hackman summer student fellowships from Franklin \& Marshall College.

\section{LITERATURE CITED}

Allen JR (1998) Suspension feeding in the brittle-star Ophiothrix fragilis: efficiency of particle retention and implications for the use of encounter-rate models. Mar Biol 132: $383-390$

Bayne BL (1993) Feeding physiology of bivalves: time-dependence and compensation for changes in food availability. In: Dame RF (ed) Bivalve filter feeders in estuarine and coastal ecosystem processes, Vol G33. NATO ASI Series, Springer-Verlag, Heidelberg, p 1-24

Berg JA, Newell RIE (1986) Temporal and spatial variations in the composition of seston available to the suspension feeder Crassostrea virginica. Estuar Coast Shelf Sci 23: 375-386

Blake JA, Maciolek NJ (1987) A redescription of Polydora cornuta Bosc (Polychaeta: Spionidae) and designation of a neotype. Bull Biol Soc Wash 7:11-15

Bock MJ, Miller DC (1996) Fluid flow and suspended particulates as determinants of polychaete feeding behavior. J Mar Res 54:565-588

Conova S (1999) Role of particle wettability in capture by a suspension-feeding crab (Emerita talpoida). Mar Biol 133: $419-428$ 
Dauer DM (1983) Functional morphology and feeding behavior of Scololepis squamata (Polychaeta: Spionidae). Mar Biol 77:279-285

Dauer DM (1985) Functional morphology and feeding behavior of Paraprionospio pinnata (Polychaeta: Spionidae). Mar Biol 85:143-151

Dauer DM (1987) Potential systematic significance of spionid polychaete tentacular morphology. Bull Biol Soc Wash 7: 41-45

Dauer DM (1994) Functional ciliary groups of the feeding palps of spionid polychaetes. Mem Mus Nat Hist 162: 81-84

Dauer DM, Maybury CA, Ewing RM (1981) Feeding behavior and general ecology of several spionid polychaetes from the Chesapeake Bay. J Exp Mar Biol Ecol 54:21-38

Dauer DM, Mahon HK, Sarda R (2003) Functional morphology and feeding behavior of Streblospio benedicti and S. shrubsolii (Polychaeta: Spionidae). Hydrobiologia 496:207-213

Fegley SR, MacDonald BA, Jacobsen TR (1992) Short-term variation in the quantity and quality of seston available to benthic suspension feeders. Estuar Coast Shelf Sci 34: $339-412$

Hentschel BT (1996) Ontogenetic changes in particle-size selection by deposit-feeding spionid polychaetes: the influence of palp size on particle contact. J Exp Mar Biol Ecol 206:1-24

Hentschel BT (2004) Sediment resuspension and boundary layer flow dramatically increase the growth rates of interface-feeding spionid polychaetes. J Mar Syst (in press)

Hughes J, Deegan LA, Peterson BJ, Holmes RM, Fry B (2000) Nitrogen flow through the food web in the oligohaline zone of a New England estuary. Ecology 81:433-452

Jordana E, Duchene JC, Charles F, Gremare A, Amouroux JM (2000) Experimental study of suspension-feeding activity in the serpulid polychaete Ditrupa arietina (O.F. Muller). J Exp Mar Biol Ecol 252:57-74

Jorgensen CB (1990) Bivalve filter feeding. Olsen \& Olsen, Fredensborg

Jumars PA, Self RFL, Nowell ARM (1982) Mechanics of particle selection by tentaculate deposit-feeders. J Exp Mar Biol Ecol 64:47-70

Kihslinger RL, Woodin SA (2000) Food patches and a surface deposit feeding spionid polychaete. Mar Ecol Prog Ser 201:233-239

LaBarbera M (1978) Particle capture by a Pacific brittle star: experimental test of the aerosol suspension feeding model. Science 201:1147-1149

LaBarbera M (1984) Feeding currents and particle capture mechanisms in suspension-feeding animals. Am Zool 24: $71-84$

Lin J, Hines AH (1994) Effects of suspended food availability on the feeding mode and burial depth of the Baltic clam, Macoma balthica. Oikos 69:28-36

Lisbjerg D, Petersen JK (2001) Feeding activity, retention efficiency, and effects of temperature and particle concentration on clearance rate in the marine bryozoan Electra crustulenta. Mar Ecol Prog Ser 215:133-141

Loo LO, Jonsson PR, Skold M, Karlsson O (1996) Passive suspension feeding in Amphiura filiformis (Echinodermata: Ophiuroidea): feeding behaviour in flume flow and potential feeding rate of field populations. Mar Ecol Prog Ser 139:143-155

Loudon C (1990) Empirical test of filtration theory: particle capture by rectangular-mesh nets. Limnol Oceanogr 35: 143-148

Lucas CH, Widdows J, Brinsley MD, Salkeld PN, Herman PMJ (2000) Benthic-pelagic exchange of microalgae at a tidal flat. 1. Pigment analysis. Mar Ecol Prog Ser 196: 59-73

Muschenheim DK (1987) The role of hydrodynamic sorting of seston in the nutrition of a benthic suspension feeder, Spio setosa (Polychaeta: Spionidae). Biol Oceanogr 4:265-288

Navarro JM, Thompson RJ (1995) Seasonal fluctuations in the size spectra, biochemical composition and nutritive value of the seston available to a suspension-feeding bivalve in a subarctic environment. Mar Ecol Prog Ser 125:95-106

Palmer MR, Nepf HM, Pettersson JR, Ackerman JD (2004) Observations of particle capture on a cylindrical collector: implications for particle accumulation and removal in aquatic systems. Limnol Oceanogr 49:76-85

Qian PY, Chia FS (1997) Structure of feeding palps and feeding behavior of the spionid polychaete Polydora polybranchia. Bull Mar Sci 60:502-511

Riisgard HU, Larsen PS (2000) Comparative ecophysiology of active zoobenthic filter feeding, essence of current knowledge. J Sea Res 44:169-193

Riisgard HU, Poulsen L, Larsen PS (1996) Phytoplankton reduction in near-bottom water caused by filter-feeding Nereis diversicolor-implications for worm growth and population grazing impact. Mar Ecol Prog Ser 141:47-54

Rossi F, Lardicci C (2002) Role of the nutritive value of sediment in regulating population dynamics of the depositfeeding polychaete Streblospio shrubsolii. Mar Biol 140: 1129-1138

Rubenstein DI, Koehl MAR (1977) The mechanisms of filter feeding: some theoretical considerations. Am Nat 111: 981-994

Shimeta J (1993) Diffusional encounter of submicrometer particles and small cells by suspension feeders. Limnol Oceanogr 38:456-465

Shimeta J, Jumars PA (1991) Physical mechanisms and rates of particle capture by suspension feeders. Oceanogr Mar Biol Annu Rev 29:191-257

Shimeta J, Koehl MAR (1997) Mechanisms of particle selection by tentaculate suspension feeders during encounter, retention, and handling. J Exp Mar Biol Ecol 209:47-73

Taghon GL, Greene RR (1992) Utilization of deposited and suspended particulate matter by benthic 'interface' feeders. Limnol Oceanogr 37:1370-1391

Taghon GL, Nowell ARM, Jumars PA (1980) Induction of suspension feeding in spionid polychaetes by high particulate fluxes. Science 210:562-564

Vedel A (1998) Phytoplankton depletion in the benthic boundary layer caused by suspension-feeding Nereis diversicolor (Polychaeta): grazing impact and effect of temperature. Mar Ecol Prog Ser 163:125-132

Velasco LA, Navarro JM (2002) Feeding physiology of infaunal (Mulinia edulis) and epifaunal (Mytilus chilensis) bivalves under a wide range of concentrations and qualities of seston. Mar Ecol Prog Ser 240:143-155

Ward JE, Shumway SE (2004) Separating the grain from the chaff: particle selection in suspension- and deposit-feeding bivalves. J Exp Mar Biol Ecol 300:83-130

Ward JE, Levinton JS, Shumway SE (2003) Influence of diet on pre-ingestive particle processing in bivalves I: Transport velocities on the ctenidium. J Exp Mar Biol Ecol 293: 129-149

Wildish D, Kristmanson D (1997) Benthic suspension feeders and flow. Cambridge University Press, Cambridge

Wilson HW (1985) Food limitation of asexual reproduction in a spionid polychaete. Int J Invertebr Reprod Devel 8: 61-65

Zajac RN, Whitlatch RB (1982) Responses of estuarine infauna to disturbance. 1. Spatial and temporal variation of initial recolonization. Mar Ecol Prog Ser 10:1-14 